THE CANADIAN JOURNAL OF AUTISM EQUITY

LA REVUE CANADIENNE DE L'ÉQUITÉ EN MATIÈRE D'AUTISME

VOLUME 1

ISSUE 1

APRIL 2021

\title{
Towards Health Equity in a National Autism Strategy: A Lens on Disparities, Barriers, and Solutions
}

\author{
Kaela Scott, University of Western Ontario, Canada \\ Megan Krasnodembski, Canadian Autism Spectrum Disorder Alliance, \\ Canada \\ Shivajan Sivapalan, SAAAC Autism Centre, Canada \\ Bonnie Brayton, DisAbled Women's Network (DAWN), Canada \\ Neil Belanger, B.C. Aboriginal Network on Disability Society, Canada \\ Robert Gagnon, Weeneebayko Area Health Authority, Canada \\ Janet McLaughlin, Wilfrid Laurier University, Canada \\ Jonathan Lai, Canadian Autism Spectrum Disorder Alliance, Canada \\ University of Toronto, Canada
}

RECOMMENDED CITATION: Scott, K., Krasnodembski, M., Sivapalan, S., Brayton, B., Belanger, N., Gagnon, R., McLaughlin, J., \& Lai, J. (2021). Towards Health Equity in a National Autism Strategy: A Lens on Disparities, Barriers, and Solutions. The Canadian Journal of Autism Equity, 1(1), 62-72. 


\title{
Toward Health Equity in a National Autism Strategy: A Lens on Disparities, Barriers, and Solutions
}

\author{
Kaela E. Scott1 (iD, Megan Krasnodembski², Shivajan Sivapalan³, Bonnie \\ Brayton ${ }^{4}$, Neil Belanger ${ }^{5}$, Robert Gagnon6 ${ }^{6}$, Janet McLaughlin7, \\ Jonathan Lai 2,8 iD
}

\begin{abstract}
Health equity allows people to reach their full health potential and access and receive care that is fair and suitable to them and their needs regardless of where they live, what they have, or who they are. To achieve health equity, equity in healthcare focuses on the role of the health system to provide timely and appropriate care. When viewed in the context of a National Autism Strategy, this extends to ensuring access to the resources that each Autistic person requires to meet their health needs, such as an autism diagnosis, services, and supports. Based on the equity panel discussion held at the Canadian Autism Leadership Summit 2020, this article reflects on the current disparities and barriers to achieving health equity in a National Autism Strategy, and outlines ways to address them. Disparities to equitable care within the autism community extend from the level of support needs of an individual to how those intersect with several key determinants of health including: geography, culture, gender, and socioeconomic status. Notably, barriers arise due to a "lack of"

theme, including lack of awareness, knowledge, access, and voice. Four reoccurring ideas were identified for how to address inequities in health care for Autistic people. First, allocate resources for regional or in-community endeavours; second, improve Autistic representation and connection; third, establish a community of allies to advocate and collaborate; and fourth, establish leadership within the community and government to make disability a priority for Canada. To achieve equity in health care in a National Autism Strategy, we need to look at the intersectionality of autism with the key determinants of health. Moreover, to effectively engage with the government, health professionals, and the public, the autism community should strive to find $a$ unified and diverse voice. And finally, conversation must turn to action.
\end{abstract}

\footnotetext{
1 University of Western Ontario, Canada

2 Canadian Autism Spectrum Disorder Alliance

3 SAAAC Autism Centre, Canada

4 DisAbled Women's Network (DAWN), Canada

5 B.C. Aboriginal Network on Disability Society, Canada

${ }^{6}$ Weeneebayko Area Health Authority

7 Wilfrid Laurier University, Canada

8 University of Toronto, Canada
} 


\section{Résumé}

L'équité en santé permet aux gens d'atteindre leur plein potentiel de santé et d'accéder et de recevoir des soins qui sont justes et adaptés à leurs besoins, peu importe où ils vivent, ce qu'ils ont ou qui ils sont. Pour atteindre l'équité en santé, il faut se concentrer sur le rôle du système de santé dans la prestation de soins appropriés et en temps opportun. Dans le contexte d'une Stratégie nationale sur l'autisme, il s'agit d'assurer l'accès aux ressources dont chaque personne autiste a besoin pour répondre à ses besoins en matière de santé, tel que le diagnostic, des services et des mesures de soutien. Basé sur la discussion du groupe d'experts sur l'équité qui s'est tenue lors du Forum canadien sur l'autisme de 2020, cet article se penche sur les disparités et les obstacles actuels à la réalisation de l'équité en santé dans le cadre d'une Stratégie nationale sur l'autisme, et présente des moyens de les éliminer. Les disparités en matière de soins équitables au sein de la communauté de l'autisme sont vastes; elles s'étendent des besoins de soutien d'une personne à la façon dont ceux-ci sont liés à plusieurs déterminants clés de la santé, notamment la géographie, la culture, le sexe et le statut socioéconomique. Les obstacles naissent notamment du thème commun des «lacunes ", y compris le manque de sensibilisation, de connaissances, d'accès et d'influence. Nous avons déterminé quatre idées récurrentes pour remédier aux inégalités en matière de soins de santé pour les personnes autistes: 1) allouer des

ressources à des projets régionaux ou communautaires; 2) améliorer la représentation des personnes autistes et la communication entre elles; 3) établir une communauté d'alliés pour défendre les intérêts des personnes autistes et collaborer avec eux; et 4) établir un leadership

au sein de la communauté et du gouvernement pour faire du handicap une priorité pour le Canada. Pour parvenir à l'équité en matière de soins de santé dans le cadre d'une Stratégie nationale sur l'autisme, nous devons examiner l'intersectionnalité entre l'autisme et les déterminants clés de la santé. De plus, pour s'engager efficacement auprès du gouvernement, des professionnels de la santé et du public, la communauté de l'autisme doit s'efforcer de trouver une voix influente, unifiée et diversifiée. Enfin, la conversation doit mener à des actions.

Keywords

Health Equity, National Autism Strategy, Disparities, Barriers, Disability, Determinants of Health Mots clés

Équité en santé, stratégie nationale sur l'autisme, disparités, obstacles, handicap, déterminants de la santé

\section{Introduction}

Health equity means striving for the highest possible standard of health for all people and giving special attention to the needs of those at greatest risk of poor health, based on social conditions (The World Health Organization, 2021). The World Health Organization (2021) defines health equity as, "the absence of avoidable or remediable differences among groups of people, whether those groups are defined socially, economically, demographically, or geographically." It implies that no one should be disadvantaged from achieving their full health potential no matter where they live, what health conditions they have, or who they are. Moreover, health equity means each individual is able to receive care that is fair and appropriate to them and their needs (Health Quality Ontario, 2017). The principles of health equity are important for Canada. As is stated in the Accessible Canada Act (2019): 
[a] all persons must have the same opportunity to make for themselves the lives that they are able and wish to have regardless of their disabilities; ... [b] laws, policies, programs, services and structures must take into account the disabilities of persons, the different ways that persons interact with their environments and the multiple and intersecting forms of marginalization and discrimination faced by persons; ... [and $\mathrm{c}$ ] persons with disabilities must be involved in the development and design of laws, policies, programs, services and structures (pp. 4 - 5).

At the Canadian Autism Leadership Summit 2020 hosted by the Canadian Autism Spectrum Disorder Alliance (CASDA), health equity was discussed in relation to the policies, programs, services, and structures needed to achieve health equity in a future National Autism Strategy in Canada. The panelists were representatives from the South Asian Autism Awareness Centre (SAAAC), Disabled Women's Network of Canada (DAWN Canada), Weeneebayko Area Health Authority (WAHA), and British Columbia Aboriginal Network on Disability Society (BCANDS) who all advocate for equitable care. They spoke on behalf of key groups including underserviced communities in central Toronto, women with disabilities, remote communities in northern Ontario, and Indigenous Peoples in British Columbia. This article reflects on the equity panel's discussion on (1) the current disparities in health equity for Autistic people, (2) the main barriers to achieving equity, and (3) ways to address these equity challenges and how the larger autism community can be effective and respectful allies in supporting equity in a National Autism Strategy.

\section{Disparities}

The panellists and discussants first reflected on where current disparities in health equity exist within the autism community. They identified five factors as major contributors to health inequity that extend from the level of support needs at an individual level and its intersection with several key determinants of health.

1. Level of support needs. As of 2013, the Diagnostic and Statistical Manual Fifth Edition separates an autism diagnosis into three "severity levels" depending on the level of support an individual needs for daily function. In fact, actual levels of need across a variety of domains (e.g. self-help, communication) are far more complex than these categories suggest, and can fluctuate throughout a person's life. Throughout Canada, however, autism funding is often based on a person's age irrespective of their needs, with many more supports available for children under five years of age than for older children, youth, and adults (e.g. "Ontario Autism Program: Childhood Budgets", 2019; "Ministry of Child and Family Development”, 2019; "Autism Canada", 2017).

2. Geography and Isolated Communities. The geographical location and jurisdiction of a community impacts the availability of services, leading to disparities in health equity. For example, northern communities in Ontario, such as the Weeneebayko area, are composed of remote and small rural municipalities that do not have the same access to supports that are 
available in larger cities. In addition to remoteness, Indigenous communities are also faced with jurisdictional issues such that health services might be provided by federal, provincial/territorial, or Indigenous self-governments resulting in a lack of adequate care due to a lack of coordination and communication between the different levels of government, agencies, and stakeholders(Thompson, 2016a, pp. 363-364).

[T] he biggest challenge is the jurisdictional issue. I think that many organizations and governments... forget that there is a provincial, territorial, and federal jurisdiction here... equity you know is a great word but isn't really a reality. - Neil Belanger, BCANDS

3. Diverse Cultural and Racialized Communities. BIPOC communities are more likely to experience both interpersonal and systemic racism, rooted in a history of colonialism, which may erode their confidence in the health care system and impede their access to services (Institute for Canadian Citizenship, 2020). Further, various religious, cultural, and immigrant communities may have specific health beliefs, first languages that are not English or French, and other culturally specific needs that should be considered and integrated into equitable and accessible health care planning.

4. Gender. Women and girls with disabilities, including Autistic women, are underserviced. Generally, gender inequities in health equity are related to inequities in employment or income (Thompson, 2016b, p. 80), but women are also overrepresented in difficult situations (e.g. violence, abuse) which affects health equity. Important for a National Autism Strategy, health inequity due to gender arises due to a lack of knowledge about how autism presents itself in girls and extends to variability in autism diagnosis (with girls more likely to be under-diagnosed or diagnosed later). This, in turn, impacts the age at which they can qualify for support and therapy services. Members of LGBTQ+ communities also face discrimination, including homophobia and transphobia, which can compound challenges accessing care.

5. Socioeconomic Status (SES). In addition, socioeconomic status compounds with these four identified disparities, as the added cost required to travel for health care services, either due to geography or residence in an underserviced area, is not financially feasible for many individuals and their families. Further, as many autism therapies and services are not provided for sufficiently in the public realm, families who can afford to purchase supports privately often do, enabling earlier access and better outcomes for families with higher SES, and further widening the chasm between income groups (McLaughlin \& Schneider, 2019, pp. 26-28). In the absence of comprehensive public services, different levels of SES amounts to two-tiered health care for many Autistic Canadians, from access to timely diagnosis (which can be purchased privately by some but not others) onward.

\section{Intersectionality}

The concept of intersectionality reflects that components of identity and determinants of 
health often compound and overlap, and cannot be considered in isolation. For example, those who experience racial or gender discrimination are also more likely to have lower SES. In fact, several of the listed disparities align with the key determinants of health as have been identified by the Public Health Agency of Canada in 2001 (Thompson, 2016b, pp. 71-80). For example, physical environment, culture, gender, and income and social status are all listed as key determinants of health. These can overlap with other determinants, such as social support networks, education and literacy, biology, social environment, and health services availability. With this in mind, we must consider the intersectionality of health equity for Autistic individuals with these key determinants of health and recognize each Autistic person's overlapping identities and experiences in order to understand the complexity of health challenges they face.

... the future is [about] partnerships that move us across those intersectional questions and begin to understand that [i.e., the intersectionality of autism]. - Bonnie Brayton, DAWN

\section{Barriers}

To achieve health equity, how the key determinants of health interact with health care for Autistic individuals needs to be recognized, and therefore, equity in health care access, availability, and administration needs to be addressed. From the discussion at the equity panel, the major barriers to achieving health care equity in underserved communities can be grouped into four categories, with an overarching lack of theme.

1. Lack of awareness. Underserviced communities themselves are not necessarily aware of the extent of inequity and the supports available for Autistic people. Often, people are not aware of available services unless they seek out those supports. This issue can arise for a variety of reasons, including intergenerational trauma that can affect trust in health care providers (particularly for Indigenous communities), language barriers, level of education (which can affect health-related conversations when heavy jargon is used), and/or access to the internet.

... these communities themselves are not aware of this inequity, to them longer wait times [and] limited access is just the norm and when it comes specifically to autismrelated services, evidence has shown that [for example] immigrant and newcomers receive a later diagnosis, which can lead to delayed access to interventions and then in turn poor outcomes.

- Dr. Shivajan Sivapalan, SAAAC

2. Lack of research and knowledge. A lack of research, specifically intersectional research, results in a lack of knowledge and evidence-based practice that can be applied variably depending on the needs of the individual. First, autism in women is under-researched. Differences in the presentation of autism in women affects diagnosis, medication, and interventions, and may also limit how and to what extent individuals and caregivers seek-out support. Second, there is a lack of culturally diverse knowledge about ASD and how preferred supports may vary based on 
culture. Third, is the lack of community-based research and knowledge; assumptions are made about what is needed for various communities and having evidence directly from those communities would help individuals in the communities to support proposed initiatives.

3. Lack of access to health services. Our panelists identified a lack of access to crucial health services as a major barrier to health equity. A lack of access to resources can arise due to geography, jurisdiction, language, racism, cost, misdiagnosis, level of education, or availability of culturally diverse education and programming. In underserviced areas, of ten the burden of service falls on a few service providers to cover a large geographical area or large number of underserviced individuals. In order to achieve health equity in a National Autism Strategy, health care equity must be a priority. This focuses on the role of the health care system to provide equitable care and extends to ensuring access to the resources that each Autistic individual requires to achieve their full potential, such as an appropriate diagnosis, services, and supports. In fact, a key determinant of health is the health services offered in a region and their method of delivery (Thompson, 2016b, p. 79).

4. Lack of voice. Underserviced communities should be able to advocate for themselves, especially since everyone's experiences and needs are different. Currently, few attempts have been made to collaborate and consult with the end-users of health services, like the communities SAAAC, DAWN Canada, WAHA, and BCANDS represent. Because of the lack of consultation and engagement directly with communities, there are assumptions made about the service needs of these groups and the barriers they face, resulting in supports that are not reflective of the needs of the community. For example, since there is no consultation with cultural minorities, currently there is an absence of culturally diverse education and programming about health in a format appropriate for the group.

\section{Ways to address health equity challenges}

The equity panel concluded by discussing how the described barriers and challenges to health equity for Autistic people can be overcome, and how the broader autism community can be effective and respectful allies in supporting equity for underserviced communities. Four reoccurring themes were identified for how to address inequities in health care for Autistic individuals.

1. Regional or in-community initiatives. The specific allocation of resources for local initiatives spanning engagement, research, education, and services can go a long way in better supporting underserviced groups, by increasing awareness, research, access, and lived-experience input. Engagement at a local level can be improved by setting up local working-groups that can (a) continue discussions on health equity, (b) facilitate community engagement, and (c) manage end-user consultations. Increasing the funding support for in-community research that is 
intersectional, inclusive, and promotes lived-experience participation will improve knowledge and evidence-based initiatives implemented in the communities. Grassroots initiatives and local workshops can be used to improve knowledge of available resources. Lastly, establishing incommunity services, such as respite programs, social/support groups for children or caregivers, therapy, and virtual care, can improve access to some health and social services.

... in community programming supports which could include things like respite services, even local events to allow children with autism to have some fun, local support, groups for parents, caregivers, and educational workshop opportunities that you know others in more urban destinations would have access to... - Robert Gagnon, WAHA

An example of such an initiative is the CARES program run by SAAAC in Toronto, Ontario which is a family support program aimed at increasing caregiver capacity to support the development of Autistic children. The program is delivered through a combination of support group discussions, expert led workshops, and social leisure activities (SAAAC Autism Centre, 2021).

2. Representation and Connection. To achieve representation, the heterogeneity of autism, beyond diagnosis, should be considered. There is a diversity of experiences across marginalized communities and everyone should be able to have a voice when it comes to establishing a strategy for health equity. One step is to ensure diverse representation on panels and in key discussion groups.

Apart from representation, the connection between and among Autistic communities and service or health care providers should be strengthened. There are several ways to improve connection, as discussed by the panelists. One way is to put a stronger focus on client-centred care. The use of cultural liaisons and creating materials in diverse formats can help health professionals connect with the communities they serve. And in response, underrepresented groups will gain an improved awareness of available health services and more readily engage with service providers.

... working with community organizations and specifically cultural liaison[s] to ensure that strategies that are being developed are actually culturally responsive ... [and] dedicating resources to create materials in different languages would help with awareness and outreach into these communities.

- Dr. Shivajan Sivapalan, SAAAC

For example, WAHA supports families and communities through health education, advocacy and Cree language services, and is committed to providing high-quality health services that include traditional and cultural healing methods (WAHA, 2021). Incorporating cultural sensitivity 
training into relevant post-secondary education fields (e.g. health professions, law school) through placement and internships will improve the cultural competency of service providers. Moreover, the autism community as a whole can work to improve their cultural knowledge and awareness, which can strengthen the relationships within the ASD community. These relationships can also be strengthened by using storytelling to convey common shared experiences, such as through the creation of "living-libraries". Storytelling distills complex language, and provides a relatable message, which can also help leaders better understand what it is that individuals with disabilities actually require.

What do they want, not us deciding what they want... let's have a conversation and start with the person who we're thinking [about]... equity means all of us working together.

- Bonnie Brayton, DAWN

3. Establish a community of allies. Unity, respect, and trust within the broader ASD community needs to be a priority. In order to effectively engage with the government, health professionals, and the public, we must try to find a unified and diverse perspective within the autism community.

[W] need to work together as a disability community, not just within autism or women with disabilities or newcomers or Indigenous. We have to start supporting each other better and get the pressure on the government and we work together as a community cohesively to move our priorities.

- Neil Belanger, BCANDS

Beyond the autism community, collaboration with underserved communities and organizations with similar barriers can be strengthened. By engaging the broader community, the shared-collective capacity to promote equity can be increased.

4. Leadership at all levels of government. To effectively promote health equity and make disability a priority for Canada, leadership at the federal, provincial/territorial, and municipal or community levels of government need to be engaged. Educating the public, health professionals, and the broader autism community, improving representation and connection, and establishing a community of allies will all increase the autism community's ability to engage with policymakers and politicians.

... but we have to understand ... anything we do is going to cost money ... disability is expensive and we need to have supportive governments. [T] he federal government is great but the provincial and territorial government is where things are going to happen. They have to be at the table, they have to be prepared to step up and that 
comes back again to who do we have in leadership positions and what is their priority of disability.

- Neil Belanger, BCANDS

In addition to these four themes, to achieve health equity in a National Autism Strategy, the criteria for "good service" should be reconsidered: what are the criteria for good service based on, who decides what those criteria are, who evaluates the criteria, and what is the purpose of the criteria (e.g. cost)? Re-evaluation needs to occur with a diverse set of livedexperience contributors by collaboratively consulting with various groups, and taking into account regional priorities and the priorities of leadership.

\section{Conclusions and Considerations}

The ways to address health equity challenges and promote change discussed in the Canadian Autism Leadership Summit 2020 equity panel reflect a broader national conversation. For instance, in the last five years, the Wellesley Institute for Health Quality Ontario (2016, p. 4), and Health Quality Ontario (2016, pp. 17 - 20; 2017, pp. 7 - 12) have identified similar actions to be taken to achieve health equity in Canada including: addressing the wide-ranging social determinants of health; access to care; empowering communities; leadership; collaboration, engagement, multi-sectoral actions; cultural and linguistic competency; and data, research and evaluation.

[M]ost important to anything ... the conversations need to turn into action. And they need ...to turn into implementation plans ... It's not only to talk about it, but to also have a coordinated strategy of how to make it happen ... no matter how many of these conversations we have, if there's no movement towards getting this towards implementation you know we're going to be lost.

- Robert Gagnon, WAHA

The panellists urged that for progress to occur, now conversation must turn to action. For example, in a policy compendium published by CASDA (2020), policy briefs were created that complement suggestions made in this equity panel and represent a step towards action. To improve regional access to services, it was recommended to create a taskforce which could guide the provinces and territories to provide universal services according to neighbourhood SES (see Affordability and Access Brief \#5, pp. 32 - 34). To increase connection between Autistic individuals and service providers, the Affordability and Access Brief \#3 (pp. 27 - 29), recommends a comprehensive training program for professionals in a wide range of sectors to expand their capacity to work with Autistic people. Establishing a community of allies with a shared, diverse voice could be achieved by encouraging and ensuring that Autistic people and service providers who are women, Indigenous, from rural and remote communities, racialized immigrants and newcomers, and from the LGBTQ+ community be prioritized as members of the board of the 
proposed advisory panel or organization for the National Autism Strategy (see Research and Governance Brief \#3, pp. 15 - 18). Recommendations to improve leadership at all levels of government included creating a cross-government leadership coordination commission (see Research and Governance Brief \#1, pp. 9 - 12) and building a collaborative framework of intergovernmental partnership in sharing knowledge and resources regarding autism (see Information Brief \#2, pp. 62 - 63).

In conclusion, the Canadian Autism Leadership Summit 2020 equity panel comprised of diverse voices discussed how to strive for health equity in a National Autism Strategy and represents progress toward consultation and collaboration. This article highlights some of the key voices from this panel. However, the panel discussion and this article should only be the beginning of these sorts of collaborations. As several of the panelists inferred - dialogue, while essential, is most helpful if it leads to action. We hope that this article spurs additional conversation, and ultimately action, on the topic of health equity for Autistic people in Canada.

\section{ORCID iD}

Kaela Scott (iD https://orcid.org/0000-0001-5707-6231

Jonathan Lai (i) https://orcid.org/0000-0002-3060-1232

\section{References}

Autism Canada. (2017). Provincial \& Territorial Funding Programs for Autism Therapy. https:// autismcanada.org/wp-content/uploads/2017/12/AC_ProgramsForAutismTherapy.pdf

CASDA. (2020). Policy Compendium: The Development of a National Autism Strategy through Community and Stakeholder Engagement. https://www.casda.ca/wp-content/uploads/2020/08/CASDA-KBHNBriefs-Compendium-_28102020-.docx.pdf

Health Quality Ontario. (2016). Health Quality Ontario's Health Equity Plan. https://www.hqontario.ca/ Portals/0/documents/health-quality/Health_Equity_Plan_Report_En.pdf

Health Quality Ontario. (2017). Health equity in the 2016/17 Quality Improvement Plans. https:// www.hqontario.ca/Portals/0/documents/qi/qip/analysis-heath-equity-2016-17-en.pdf

Institute for Canadian Citizenship. (2020). Racism in Canada's health-care system was a risk to BIPOC Canadians before COVID-19. Retrieved April 01, 2021, from https://www.inclusion.ca/article/ racism-in-canadas-health-care-system-was-a-risk-to-bipoc-canadians-before-covid-19/

Legislative Branch. (S.C. 2019, c. 10). Accessible Canada Act. https: / /laws-lois.justice.gc.ca/PDF/ A-0.6.pdf

McLaughlin, J. and Schneider, M. (2019). Autism Services in Ontario: Impacts on Family and Child WellBeing-Research Summary, Laurier Autism Research Consortium Report. https://www.wlu.ca/ academics/faculties/faculty-of-human-and-social-sciences/faculty-profiles/janet-mclaughlin/larc/ assets/documents/larc-report.pdf. Ministry of Child and Family Development. (2019, September 25). How much funding is available. Retrieved March 01, 2021, from https://www2.gov.bc.ca/gov/ content/health/managing-your-health/child-behaviour-development/special-needs/autismspectrum-disorder/autism-funding/funding-amount

Ontario Autism Program: Childhood budgets. (2019, October 4). Retrieved March 01, 2021, from https:// www.ontario.ca/page/ontario-autism-program-childhood-budgets\#section-6

SAAAC Autism Centre. (2020, January 15). SAAAC CARES. SAAAC. Retrieved March 07, 2021, from https:// saaac.org/programs/

Thompson, V. D. (2016a). Population health: Introduction and principles. In Health and health care delivery in Canada (2nd ed., pp. 363-364). Toronto, ON: Elsevier. 
Thompson, V. D. (2016b). Current Issues and future Tends in Health Care in Canada. In Health and health care delivery in Canada (2nd ed., pp. 71-80). Toronto, ON: Elsevier.

WAHA. (2021). Mission, Vision and Values - Weeneebayko Area Health Authority. Weeneebayko Area Health Authority. Retrieved March 07, 2021, from https://www.waha.ca/mission/

Wellesley Institute for Health Quality Ontario. (2016). International Review of Health Equity Strategies: Executive Summary. https: / /www.wellesleyinstitute.com/wp-content/uploads/2016/07/ International-Review-of-Health-Equity-Strategies-Executive-Summary.pdf

World Health Organization. (2021). Social Determinants of Health. Retrieved March 01, 2021, from www.who.int/health-topics/social-determinants-of-health 